\title{
Determination of Dialysis Dose: A Clinical Comparison of Methods
}

\author{
Peter Ahrenholz ${ }^{a}$ Petr Taborsky ${ }^{\prime}$ Margot Bohling ${ }^{b}$ Peter Rawer ${ }^{c}$ Noureddin Ibrahim ${ }^{d}$ \\ Martin Gajdos $^{m}$ Petr Machek ${ }^{n}$ Michaela Sagova ${ }^{\circ}$ Hans Gruber $^{\mathrm{e}}$ Pavel Moucka $^{\mathrm{p}}$ \\ Ivan Rychlik ${ }^{q}$ Gerd Leimenstoll ${ }^{f}$ Pavel Vyskocil ${ }^{r} \quad$ Gunter Toenne $^{g} \quad$ Jindriska Possnickerova ${ }^{s}$ \\ Joerg Woggan $^{\mathrm{h}}$ Werner Riegel $^{\mathrm{i}}$ Helmut Schneider ${ }^{j}$ Ralf Wojke ${ }^{\mathrm{k}}$ \\ ${ }^{a}$ BioArtProducts $\mathrm{GmbH}$, Rostock, ${ }^{\mathrm{b}}$ Dialysis Centre Wilhelmshaven, ${ }^{\mathrm{C}}$ Dialysis Centre Wetzlar, ${ }^{\mathrm{d}}$ Dialysis Centre Döbeln, \\ e Dialysis Centre Landshut, fDialysis Centre Kiel, ${ }^{g}$ Dialysis Centre Warendorf, hDialysis Centre \\ Hamburg-Poppenbuettel, ' Klinikum Darmstadt, j'Dialysis Centre Harsewinkel, and kFME, Clinical Research, \\ Bad Homburg, Germany; 'FME Dialysis Centre Prague 4, 'mFME Dialysis Centre Sokolov, ${ }^{\mathrm{m}} \mathrm{FME}$ Dialysis Centre Most, \\ -FME Dialysis Centre Prague 5, ${ }^{\mathrm{P} F M E}$ Dialysis Centre Kolin, ${ }^{\mathrm{q}} \mathrm{FME}$ Dialysis Centre Prague 10, ${ }^{\mathrm{F}} \mathrm{FME}$ Dialysis Centre \\ Louny, and ${ }^{\mathrm{F}} \mathrm{FME}$ Dialysis Centre Chomutov, Czech Republic
}

\section{Key Words}

Delivered dialysis dose $\cdot$ Comparison of methods .

Online clearance measurement $\cdot$ Hemodialysis $\cdot$ Online hemodiafiltration

\begin{abstract}
Background: Guidelines recommend regular measurements of the delivered hemodialysis dose Kt/V. Nowadays, automatic non-invasive online measurements are available as alternatives to the conventional method with blood sampling, laboratory analysis, and calculation. Methods: In a prospective clinical trial, three different methods determining dialysis dose were simultaneously applied: $\mathrm{Kt} / \mathrm{V}_{\text {Dau }}$ (conventional method with Daugirdas' formula), $\mathrm{Kt} / \mathrm{V}_{\mathrm{OCM}}$ [online clearance measurement (OCM) with urea distribution volume $\mathrm{V}$ based on anthropometric estimate], and $\mathrm{Kt} / \mathrm{V}_{\mathrm{BCM}}$ [OCM measurement with $\mathrm{V}$ measured by bioimpedance analysis (Body Composition Monitor)]. Results: 1,076 hemodialysis patients were analyzed. The dialysis dose was measured as Kt $/ \mathrm{V}_{\text {Dau }}=1.74 \pm 0.45, \mathrm{Kt} / \mathrm{V}_{\mathrm{OCM}}=1.47 \pm 0.34$, and $\mathrm{Kt} / \mathrm{V}_{\mathrm{BCM}}=1.65 \pm 0.42$. The difference between $\mathrm{Kt} / \mathrm{V}_{\mathrm{OCM}}$ and $\mathrm{Kt} / \mathrm{V}_{\mathrm{BCM}}$ was due to the difference between anthropometric
\end{abstract}

estimated $\mathrm{V}_{\text {Watson }}$ and measured $\mathrm{V}_{\mathrm{BCM}}$. Compared to $\mathrm{Kt} / \mathrm{V}_{\text {Daur }}$ $\mathrm{Kt} / \mathrm{V}_{\mathrm{OCM}}$ was $15 \%$ lower and $\mathrm{Kt} / \mathrm{V}_{\mathrm{BCM}} 5 \%$ lower. $\mathrm{Kt} / \mathrm{V}_{\text {Dau }}$ was incidentally prone to falsely high values due to operative errors, whereas in these cases OCM-based measurements Kt/ $\mathrm{V}_{\mathrm{OCM}}$ and $\mathrm{Kt} / \mathrm{V}_{\mathrm{BCM}}$ delivered realistic values. Conclusions: The automated OCM Kt/ $\mathrm{V}_{\mathrm{OCM}}$ with anthropometric estimation of urea distribution volume was the easiest method to use, but $\mathrm{Kt} / \mathrm{V}_{\mathrm{BCM}}$ with measured urea distribution volume was closer to the conventional method.

Copyright $\odot 2011$ S. Karger AG, Basel

\section{Introduction}

An essential quality parameter of chronic hemodialysis (HD) therapy is the delivered dialysis dose. The European Best Practice Guidelines recommended as minimum treatment dose an equilibrated $\mathrm{Kt} / \mathrm{V}=1.2$ [1], but in clinical practice this value cannot be achieved for every patient $[2,3]$.

According to the guidelines, dialysis dose should be measured using a validated method [1]. Apart from blood sample-based methods, alternative methods determin- 
ing dialysis dose have been developed, mostly based on measurements of conductivity [4], [5] or of urea [6], recently also of ultraviolet absorbance in the spent dialysate [7].

The standard method determining dialysis dose consists of three steps: pre- and postdialytic blood samples, postdialytic laboratory analysis of the urea concentration, and finally, application of urea kinetic modeling or - more commonly used - of the Daugirdas' secondgeneration formula [8] (Kt/ $\left.\mathrm{V}_{\text {Dau }}\right)$. According to the guidelines, dialysis dose should be measured at least monthly [1], although in some dialysis centers this dose determination is done by the standard method with lower frequency, e.g. quarterly.

The latest generation of dialysis machines incorporates as standard features the technology which allows automatically measuring the dialysis dose without blood sampling in every dialysis treatment $[9,10]$, such as the Online Clearance Monitor OCM [4].

The effective cleared plasma Kt (K: urea clearance, $\mathrm{t}$ : effective dialysis duration) is delivered by automatic measurements and calculations; in order to obtain the dialysis dose $\mathrm{Kt} / \mathrm{V}$ the urea distribution volume $\mathrm{V}$ is mandatory. Several anthropometric estimations are known; mostly the Watson estimation [11] is applied. The second method applied in this clinical study is the dialysis dose measured by OCM using the Watson estimation for $\mathrm{V}$ $\left(\mathrm{Kt} / \mathrm{V}_{\mathrm{OCM}}\right)$.

Instead of an anthropometric estimation, the urea distribution volume $\mathrm{V}$ can be measured predialytically by bioimpedance spectroscopy (Body Composition Monitor, BCM) [12-18]. The third method applied in this clinical study is the automatic online clearance measurement $(\mathrm{OCM})$ with $\mathrm{V}$ measured by $\mathrm{BCM}\left(\mathrm{Kt} / \mathrm{V}_{\mathrm{BCM}}\right)$.

The aim of this prospective clinical trial was the comparison over a wide range of dialysis doses of the three methods, $\mathrm{Kt} / \mathrm{V}_{\mathrm{Dau}}, \mathrm{Kt} / \mathrm{V}_{\mathrm{OCM}}$, and $\mathrm{Kt} / \mathrm{V}_{\mathrm{BCM}}$, which are presently applied in dialysis centers. It is discussed how these different methods may support the clinicians to achieve the recommended dialysis dose. In order to obtain an adequate overview with sufficient clinical data, many European dialysis centers participated in this clinical trial.

\section{Materials and Methods}

Design

The clinical trial was designed as a prospective, observational, cross-sectional, international, multicenter study comparing simultaneously three different methods of dialysis dose assessment in clinical routine: $\mathrm{Kt} / \mathrm{V}_{\mathrm{Dau}}, \mathrm{Kt} / \mathrm{V}_{\mathrm{OCM}}$, and $\mathrm{Kt} / \mathrm{V}_{\mathrm{BCM}}$.
Due to the observational nature of the study, no additional blood samples were taken, benefitting from the regularly performed dialysis dose measurements with pre- and postdialytic blood samples in order to obtain the dialysis dose $\mathrm{Kt} / \mathrm{V}_{\text {Dau }}$.

Simultaneously to the standard method, the dialysis dose was also determined by two different non-invasive methods: (1) Kt/ $\mathrm{V}_{\mathrm{OCM}}$ was automatically measured by OCM with the urea distribution volume $\mathrm{V}$ based on the anthropometric estimation of Watson, and (2) Kt/ $\mathrm{V}_{\mathrm{BCM}}$ was determined from the automatically measured Kt, derived by OCM, with $\mathrm{V}$, determined from a predialytic BCM measurement.

\section{Patient Selection}

The trial was planned as a study with all eligible patients of each study center, thus a cross-section of those patients complying with the inclusion criteria (adult age, physical and mental ability to participate in the study, treatment with HD or online hemodiafiltration (online HDF) [19], and signed informed consent). Exclusion criteria were pregnancy (a standard criterion in case of female patients), single-needle dialysis (OCMs were developed for double-needle dialysis), pacemaker or implanted pump (possible interferences with the bioimpedance measurement), and major amputation of arm or leg (resulting in reduced accuracies of bioimpedance measurements).

\section{Study Parameters}

Patient characteristics (such as age, sex, height, weight, residual renal function), medical history, comorbidities and treatment modality (HD or online HDF) were recorded at study entry by trained physicians. The pre- and postdialytic urea concentrations (measured decentrally in the laboratories of the centers) were recorded.

The following treatment parameters were noted: pre- and postdialytic body weight, ultrafiltration volume, volume of processed blood, effective dialysis time, and the dialysis dose Kt/ $\mathrm{V}_{\mathrm{OCM}}$. From the predialytic BCM measurement the urea distribution volume $\mathrm{V}$ was determined as predialytic total body water corrected by the achieved weight loss during treatment.

\section{Technical Description}

The dialysis monitors applied in the trial were 4008 and 5008 monitors (both Fresenius Medical Care, Bad Homburg, Germany) enabling both treatment modes, HD and online HDF, and with Online Clearance Monitor (OCM).

The OCM automatically determines the urea clearance $\mathrm{K}$ via a positive or negative conductivity bolus, based not solely on a single measurement, but on several consecutive measurements evenly spread over the dialysis treatment. With $\mathrm{K}$ and the effective dialysis duration $\mathrm{t}$ given, the effective cleared plasma Kt is easily calculated. For the urea distribution volume V, different options for anthropometric estimations are available in the dialysis monitor 4008 and 5008; mostly the Watson estimation is applied, resulting in the dialysis dose $\mathrm{Kt} / \mathrm{V}_{\mathrm{OCM}}$.

Multifrequency bioimpedance analysis has been shown to be a simple, safe and inexpensive method to measure the different water compartments of the human body [14]. The Body Composition Monitor (BCM; Fresenius Medical Care) is a stand-alone device that has been shown to be a precise technique when compared to dilution methods of suited markers (e.g. deuterium or tritium for determination of total body water, or bromide for determina- 
tion of extracellular water are widely accepted, but not practical in clinical routine); it has been described and evaluated in more detail elsewhere $[13,15,17,18]$, both in healthy subjects and in HD patients.

The predialytic BCM measurement determined the urea distribution volume $\mathrm{V}$ after placement of the electrodes on hand and foot; this measurement was observational and did not influence the subsequent $\mathrm{HD}$ treatment.

The dialysis dose $\mathrm{Kt} / \mathrm{V}_{\mathrm{BCM}}$ is determined from this predialytic urea distribution volume $\mathrm{V}$, the achieved weight loss during the treatment, and the OCM measurement of Kt.

\section{Regulatory Aspects}

In all dialysis centers the applicable local legal and administrative regulations were followed and approvals of ethics committees were obtained. The patients were informed and signed their consent. The clinical trial was registered at the German Clinical Study Registry with Trial No. DRKS00000499, see for example the International Clinical Trials Registry Platform of the World Health Organization.

\section{Statistics}

Continuous variables are presented as mean and standard deviation, for categorical variables absolute and relative percentages are given. Agreement of Kt/V measurements was assessed by creating Bland-Altman plots [20]. Additionally, correlation coefficients according to Pearson and concordance coefficients according to Lin [21] were calculated. All analyses were performed with SAS version 9.2.

\section{Results}

\section{Patient Population}

1,606 patients from 18 dialysis centers were screened whether eligible for the study, 1,089 patients could be recruited, and 1,076 patients could be analyzed. The age of the 529 non-analyzed patients was $69.0 \pm 13.4$ years, and $55.6 \%$ were males; the age of the 1,076 patients of the analysis cohort was $65.7 \pm 13.9$ years, and $57.0 \%$ were males. The slight difference in mean age (3.3 years) might be due to the exclusion of patients with pacemakers, implanted pumps, amputations, physical and mental problems in the study population.

In the analysis cohort the underlying renal diseases originated from diabetic nephropathy (26\%), hypertensive nephropathy $(15 \%)$, glomerulonephritis $(13 \%)$, interstitial nephritis (10\%), polycystic nephropathy (9\%), nephrosclerosis (6\%), vascular disease (4\%), pyelonephritis (3\%), congenital disease (2\%), and analgetic nephropathy $(1 \%)$, the remaining diseases were of other origin or unknown.

The characteristics of the analysis cohort are shown in table 1 , for all patients as well as separated for the treat-
Table 1. Patients' characteristics for the whole analysis cohort, and separate for treatment modes HD and online HDF

\begin{tabular}{|c|c|c|c|}
\hline & $\begin{array}{l}\text { All } \\
\text { patients } \\
(\mathrm{n}=1,076)\end{array}$ & $\begin{array}{l}\text { Patients } \\
\text { on HD } \\
(n=407)\end{array}$ & $\begin{array}{l}\text { Patients } \\
\text { on oHDF } \\
(n=669)\end{array}$ \\
\hline Age, years & $66.0 \pm 13.9$ & $69.3 \pm 13.2$ & $63.9 \pm 13.9$ \\
\hline Sex, \% male & 57.0 & 54.5 & 58.4 \\
\hline Body mass index, $\mathrm{kg} / \mathrm{m}^{2}$ & $26.1 \pm 5.2$ & $26.0 \pm 5.1$ & $26.1 \pm 5.2$ \\
\hline \multicolumn{4}{|l|}{ Urine volume $/$ day $^{1}, \%$} \\
\hline low/medium/high & $30 / 25 / 45$ & $21 / 22 / 57$ & $36 / 26 / 38$ \\
\hline
\end{tabular}

Data are expressed as number $(\mathrm{n})$, mean $\pm \mathrm{SD}$, or percentage.

${ }^{1}$ Urine volume/day: low: $<100 \mathrm{ml} /$ day, medium; $\leq 500 \mathrm{ml} /$ day, high: $>500 \mathrm{ml} /$ day.

Table 2. Treatment and related data for patients of the whole analysis cohort and separate for treatment modes HD and online HDF

\begin{tabular}{|c|c|c|c|}
\hline & $\begin{array}{l}\text { All } \\
\text { patients } \\
(\mathrm{n}=1,076)\end{array}$ & $\begin{array}{l}\text { Patients } \\
\text { on } \mathrm{HD} \\
(\mathrm{n}=407)\end{array}$ & $\begin{array}{l}\text { Patients } \\
\text { on oHDF } \\
(n=669)\end{array}$ \\
\hline Predialytic weight, $\mathrm{kg}$ & $76.5 \pm 16.9$ & $75.5 \pm 16.6$ & $77.1 \pm 17.1$ \\
\hline Postdialytic weight, kg & $74.6 \pm 16.6$ & $73.9 \pm 16.3$ & $75.1 \pm 16.8$ \\
\hline Ultrafiltration volume, 1 & $2.34 \pm 1.21$ & $1.97 \pm 1.19$ & $2.57 \pm 1.17$ \\
\hline \multicolumn{4}{|l|}{ Volume of processed } \\
\hline blood, 1 & $82.7 \pm 19.3$ & $73.4 \pm 18.4$ & $88.4 \pm 17.5$ \\
\hline Dialysis duration, min & $261 \pm 28$ & $251 \pm 28$ & $266 \pm 27$ \\
\hline
\end{tabular}

Data expressed as mean $\pm \mathrm{SD}$.

ment modes HD and online HDF. Body mass index was nearly identical in the HD patients and in the online HDF patients, small differences were observed for age, sex and residual renal function: patients treated with online HDF were slightly younger (-5.4 years), had a higher percentage of males $(+4 \%)$, and a lower residual renal function (15\% more anuric patients).

\section{Treatment Parameters}

An overview of the mean patient and treatment parameters is given in table 2. Differences were seen between patients treated by HD and online HDF: for online HDF, higher mean values were observed for body weight (predialytic body weight: $+1.6 \mathrm{~kg}$, postdialytic body weight: $+1.2 \mathrm{~kg})$, ultrafiltration volume (+0.6 liter), volume of processed blood (+15 liters), and treatment duration (+15 min). 
Table 3. Dialysis dose data of the whole analysis cohort and separate for treatment modes HD and online HDF

\begin{tabular}{llll}
\hline & $\begin{array}{l}\text { All } \\
\text { patients } \\
(\mathrm{n}=1,076)\end{array}$ & $\begin{array}{l}\text { Patients } \\
\text { on HD } \\
(\mathrm{n}=407)\end{array}$ & $\begin{array}{l}\text { Patients } \\
\text { on oHDF } \\
(\mathrm{n}=669)\end{array}$ \\
\hline $\mathrm{V}_{\text {Watson }}, 1$ & $37.5 \pm 7.0$ & $36.8 \pm 7.0$ & $37.9 \pm 7.1$ \\
$\mathrm{~V}_{\mathrm{BCM}}, 1$ & $33.9 \pm 7.2$ & $33.7 \pm 7.1$ & $34.0 \pm 7.3$ \\
$\mathrm{Kt} / \mathrm{V}_{\text {Dau }}$ & $1.74 \pm 0.45$ & $1.51 \pm 0.40$ & $1.87 \pm 0.43$ \\
$\mathrm{Kt} / \mathrm{V}_{\mathrm{OCM}}$ & $1.47 \pm 0.34$ & $1.30 \pm 0.30$ & $1.58 \pm 0.32$ \\
$\mathrm{Kt} / \mathrm{V}_{\mathrm{BCM}}$ & $1.65 \pm 0.42$ & $1.44 \pm 0.37$ & $1.77 \pm 0.40$ \\
\hline
\end{tabular}

Urea distribution volume $\mathrm{V}$ based on the anthropometric estimation of Watson $\left(\mathrm{V}_{\text {Watson }}\right)$ and based on Body Composition Monitor measurements $\left(\mathrm{V}_{\mathrm{BCM}}\right)$, and dialysis doses measured with different methods $\left(\mathrm{Kt} / \mathrm{V}_{\text {Dau }}, \mathrm{Kt} / \mathrm{V}_{\mathrm{OCM}}, \mathrm{Kt} / \mathrm{V}_{\mathrm{BCM}}\right)$. Data are expressed as mean $\pm \mathrm{SD}$.

Mean predialytic values measured by BCM were a total body water $\mathrm{V}$ of $35.8 \pm 7.5$ liters, extracellular water of $17.6 \pm 3.6$ liters, lean tissue index of $12.3 \pm 2.9 \mathrm{~kg} / \mathrm{m}^{2}$, and overhydration of $1.9 \pm 1.6$ liters.

\section{Dialysis Dose Data}

The mean dialysis dose data are given in table 3 . The mean dialysis dose was the highest when measured by the standard method with blood samples, whereas the automatic OCM method with the urea distribution volume estimate according to Watson provided the lowest value. The value of the method with Kt measured by OCM and $\mathrm{V}$ measured by BCM was in between, closer to $\mathrm{Kt} / \mathrm{V}_{\mathrm{Dau}}$. The difference between $\mathrm{Kt} / \mathrm{V}_{\mathrm{OCM}}$ and $\mathrm{Kt} / \mathrm{V}_{\mathrm{BCM}}$ was due to the difference in $\mathrm{V}$.

Dialysis doses are given also separately for patients treated by HD or online HDF in table 3. Independently from the applied method, the mean dialysis dose was higher for online $\mathrm{HDF}$ than for $\mathrm{HD} ; \mathrm{Kt} / \mathrm{V}_{\mathrm{Dau}}:+0.36$ (+24\%), Kt/ $\mathrm{V}_{\mathrm{OCM}}:+0.28(+22 \%)$, and $\mathrm{Kt} / \mathrm{V}_{\mathrm{BCM}}:+0.33$ $(+23 \%)$.

The distribution of the measured dialysis doses is shown by a box-and-whisker plot in figure 1. Outliers with dialysis dose values $>5$ were incidentally observed for $\mathrm{Kt} / \mathrm{V}_{\mathrm{Dau}}$ (possible blood sampling or laboratory errors), whereas in the same patients the OCM-based dialysis dose measurements $\mathrm{Kt} / \mathrm{V}_{\mathrm{OCM}}$ and $\mathrm{Kt} / \mathrm{V}_{\mathrm{BCM}}$ delivered much lower values in the usual range.

The relation between $\mathrm{Kt} / \mathrm{V}_{\text {Dau }}$ and $\mathrm{Kt} / \mathrm{V}_{\mathrm{BCM}}$ is shown in figure 2. The correlation between these methods was high: Pearson's correlation coefficient between $\mathrm{Kt} / \mathrm{V}_{\text {Dau }}$ and $\mathrm{Kt} / \mathrm{V}_{\mathrm{BCM}}$ was 0.82 (if the probable errors with values

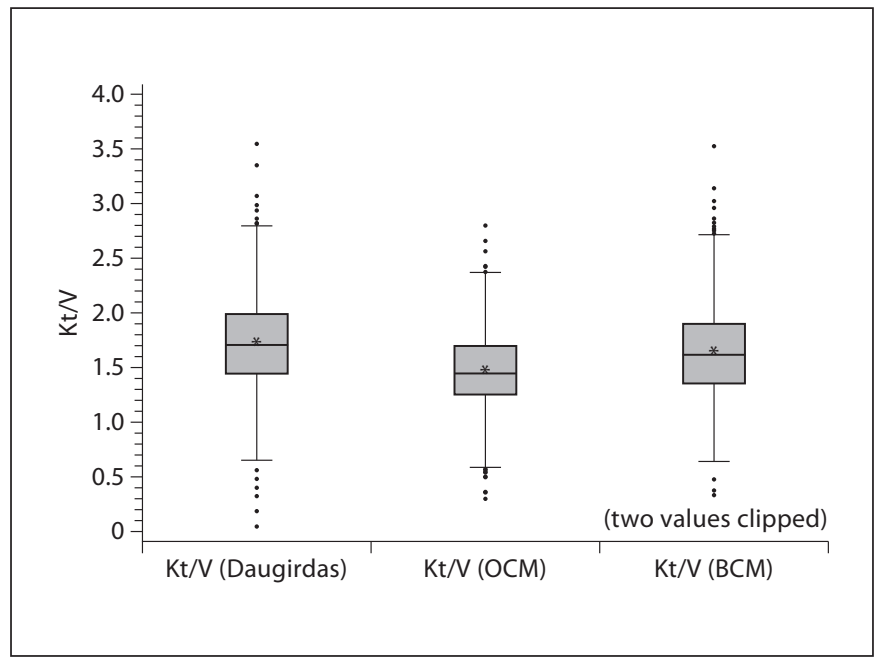

Fig. 1. Box-and-whisker plot of the distribution of dialysis doses as measured by three different methods: $\mathrm{Kt} / \mathrm{V}_{\mathrm{OCM}}$, the automatic OCM with the urea distribution volume $\mathrm{V}$ based on the anthropometric estimation of Watson, $\mathrm{Kt} / \mathrm{V}_{\mathrm{BCM}}$, the automatic OCM with the urea distribution volume $\mathrm{V}$ measured by the BCM, and $\mathrm{Kt} / \mathrm{V}_{\text {Dau }}$, the conventional blood sampling method applying Daugirdas' formula. Half of all values are within the grey box; the median in the box separates the central quartiles. The mean value (see also table 3 ) is shown as an asterisk. For $\mathrm{Kt} / \mathrm{V}_{\text {Dau }}$ two values (5.3 and 6.7, most probably blood sampling or laboratory errors) are outside the scale and not shown in this figure.

$>5$ were neglected). In this case, Lin's concordance coefficient with a value of 0.81 also suggested good agreement.

A Bland-Altman analysis of agreement between Kt/ $\mathrm{V}_{\text {Dau }}$ and $\mathrm{Kt} / \mathrm{V}_{\mathrm{BCM}}$ was performed (fig. 3). The mean difference in dialysis dose was 0.084 , and the $95 \%$ agreement interval was limited by -0.404 and +0.572 . On average, $\mathrm{Kt} / \mathrm{V}_{\mathrm{OCM}}$ resulted in $15 \%$ lower values compared to $\mathrm{Kt} /$ $\mathrm{V}_{\mathrm{Dau}}$, and $\mathrm{Kt} / \mathrm{V}_{\mathrm{BCM}}$ had $5 \%$ lower values compared to Kt/ $\mathrm{V}_{\text {Dau. }}$.

\section{Discussion}

As a key performance indicator of dialysis quality the delivered dialysis dose should be monitored closely. Three different methods determining dialysis dose were investigated simultaneously in this prospective clinical trial. Dialysis dose was determined by the conventional method with blood sampling and calculation $\left(\mathrm{Kt} / \mathrm{V}_{\text {Dau }}\right)$, by automatic OCM with a urea distribution volume $\mathrm{V}$ based on anthropometric estimation $\left(\mathrm{Kt} / \mathrm{V}_{\mathrm{OCM}}\right)$, and by auto- 


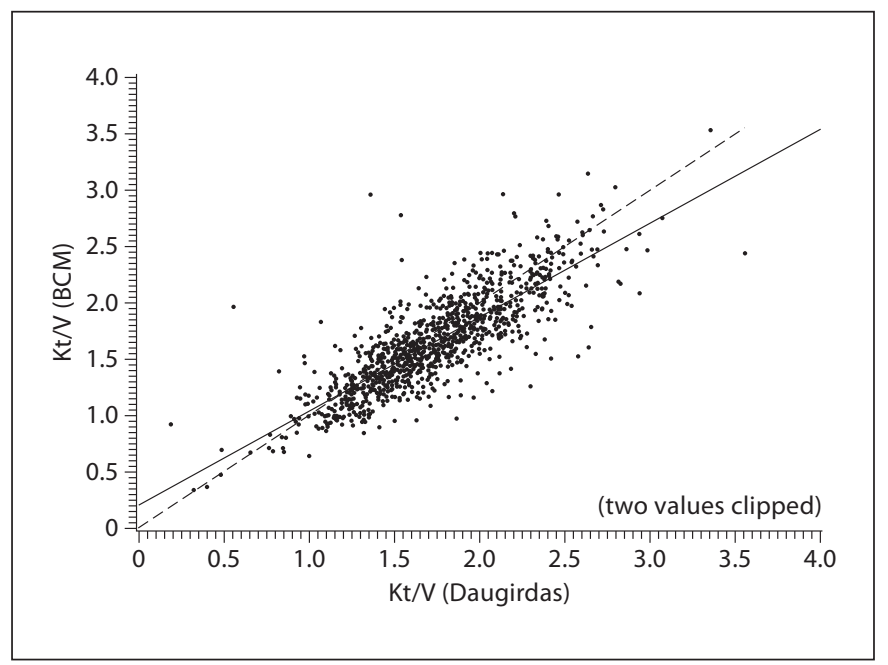

Fig. 2. Comparison of dialysis doses for conventional method (Kt/ $\mathrm{V}_{\text {Dau }}$ ) and automatic online clearance method with urea distribution volume measured by $\mathrm{BCM}\left(\mathrm{Kt} / \mathrm{V}_{\mathrm{BCM}}\right)$ including regression line and line of identity. For $\mathrm{Kt} / \mathrm{V}_{\mathrm{Dau}}$ two values outside the scale are not shown in this figure.

matic OCM with urea distribution volume $\mathrm{V}\left(\mathrm{Kt} / \mathrm{V}_{\mathrm{BCM}}\right)$ measured by BCM. For this comparison both the number of European dialysis centers and the number of their patients was large enough in order to obtain representative data: 18 centers participated and 1,076 patients were analyzed.

As expected, the methods determining dialysis dose did not give identical results. For simultaneous application of these methods we observed mean values $\mathrm{Kt} / \mathrm{V}_{\text {Dau }}$ $>\mathrm{Kt} / \mathrm{V}_{\mathrm{BCM}}>\mathrm{Kt} / \mathrm{V}_{\mathrm{OCM}}$. The mean difference between Kt/ $\mathrm{V}_{\mathrm{OCM}}$ and $\mathrm{Kt} / \mathrm{V}_{\text {Dau }}$ was 0.27 , and between $\mathrm{Kt} / \mathrm{V}_{\mathrm{BCM}}$ and $\mathrm{Kt} / \mathrm{V}_{\text {Dau }}$ it was 0.09 . Nevertheless, the differences between these methods were observed to be proportional, demonstrated by a similarly higher mean dialysis dose for online HDF compared to HD: Kt/ $/ \mathrm{V}_{\text {Dau }}:+24 \%, \mathrm{Kt} / \mathrm{V}_{\mathrm{OCM}}$ : $+22 \%$, and $\mathrm{Kt} / \mathrm{V}_{\mathrm{BCM}}:+23 \%$.

The benefits and drawbacks of different methods to determine dialysis dose have been discussed earlier $[1,22$, 23], and only a few arguments should be called to mind here.

Concerning the conventional method it should be kept in mind that methods based on blood sampling are critical concerning proper timing, compliance with recommended methods, and are known for occasional mistakes in handling, storage or transport of the samples or in laboratory errors of measuring urea $[8,23-28]$. With the conventional method, $\mathrm{Kt} / \mathrm{V}_{\text {Dau }}$, we found two measure-

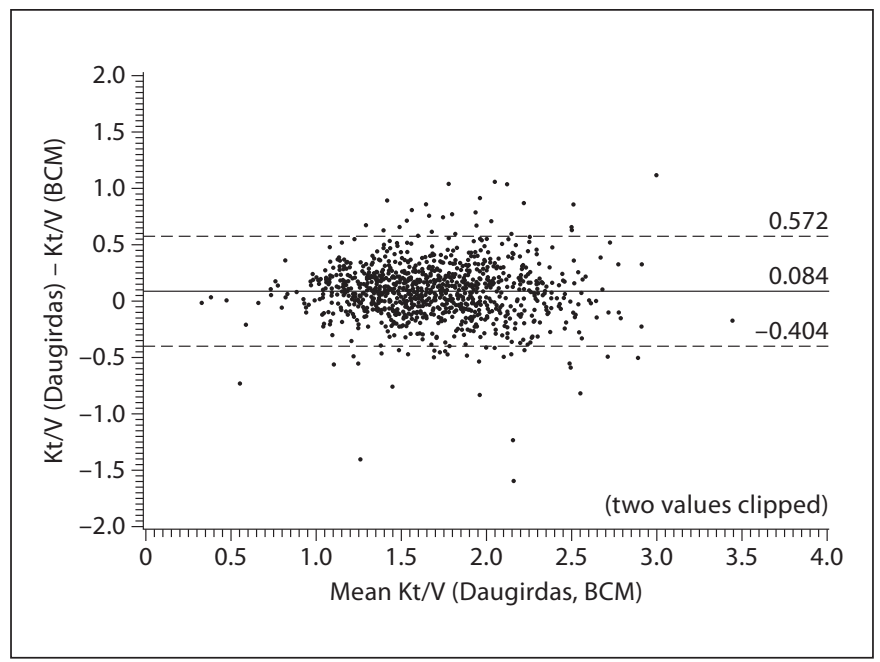

Fig. 3. Bland-Altman plot for the differences between the conventional method with urea concentrations from blood samples and Daugirdas' formula $\left(\mathrm{Kt} / \mathrm{V}_{\text {Dau }}\right)$, and the automatic OCM with the urea distribution volume $\mathrm{V}$ measured by the $\mathrm{BCM}\left(\mathrm{Kt} / \mathrm{V}_{\mathrm{BCM}}\right)$. For $\mathrm{Kt} / \mathrm{V}_{\text {Dau }}$ two values outside the scale are not shown.

ments with dialysis dose values $>5$, whereas the OCMbased methods, $\mathrm{Kt} / \mathrm{V}_{\mathrm{OCM}}$ and $\mathrm{Kt} / \mathrm{V}_{\mathrm{BCM}}$, delivered plausible values for the same treatments. The second-generation Daugirdas' formula was modeled from $500 \mathrm{HD}$ sessions, and its total error remains in an acceptable 5\% range throughout the investigated range of dialysis doses $(0.7 \leq \mathrm{Kt} / \mathrm{V} \leq 2.0)$ [8]. This method is one out of several methods with significant differences, but it is established as standard in clinical routine $[22,23]$.

The standard method means a blood loss for the patient and additional costs for the healthcare provider, therefore it is not done in every single treatment.

If the dialysis dose is measured with a low frequency (e.g. required only every 3 months in Germany) deteriorations in dialysis quality may occur, and remain undetected for weeks or maybe for months. Even when there are no apparent changes in therapy, the delivered dialysis dose may vary considerably from treatment to treatment [29], and cannot be considered stable [30].

Any discrepancy between the prescribed and the delivered dialysis dose can yield valuable diagnostic information [9], and each additional dialysis dose measurement enables an early detection. Avoiding discrepancies between the prescribed and the delivered dose calls for a continuous surveillance [31]. Measuring the dialysis dose automatically in every dialysis treatment enables early countermeasures in order to maintain the recommended 
level of dialysis dose [30]. Even for a high delivered dialysis dose, an unexpected decrease of the dialysis dose may be an indicator for problems with the treatment procedure itself (e.g. delivered blood flow rate lower than displayed by the monitor, or beginning clotting in dialyzer) or for problems with blood access (e.g. decreasing shunt flow due to developing stenosis).

An automatic measurement of the dialysis dose during every dialysis session does no harm to the patient, as no blood samples are taken. For patients with a constant dialysis dose $>1.6$ the benefit of an automatic measurement may be moderate, but for patients with varying and lower dialysis doses the risk of an undetected low dialysis dose for longer periods of time are real, and the benefit of continuous surveillance concerning dose delivery seems obvious.

Although the OCM accurately measures both urea clearance K and effective dialysis duration $t$, the accuracy of the urea distribution volume $\mathrm{V}$ is lower, if anthropometric formulae are used. The commonly used Watson formula was derived from 723 adults obtained from dilution studies. It can be applied in the dialysis monitors 4008 and 5008. Meanwhile, this estimation was found to overestimate the total body water of HD patients $[12,16$, $32-35$ ] and consequently a dialysis dose based on this formula is often underestimated.

The accuracy of BCM determining total body water was evaluated earlier against available gold standard ref- erence methods, and agreement with clinical assessment of fluid status was demonstrated $[13,17,18]$, both for healthy subjects and HD patients. Meanwhile, hydration status measured by BCM has been shown to be an independent predictor of mortality in chronic HD patients [36].

In our study the predialytic BCM measurement and a mean weight loss of $1.9 \mathrm{~kg}$ delivered a mean urea distribution volume $\mathrm{V}$ of 33.9 liters, which was 3.6 liters lower than the Watson estimation. Due to this lower volume the mean dialysis dose $\mathrm{Kt} / \mathrm{V}_{\mathrm{BCM}}$ (with all parameters $\mathrm{K}$, $\mathrm{t}$, and $\mathrm{V}$ measured) was found higher than the mean dialysis dose $\mathrm{Kt} / \mathrm{V}_{\mathrm{OCM}}$ and close to the standard method.

In conclusion, this clinical trial demonstrated that due to the automated procedure the OCM with the Watson estimation for urea distribution volume was easiest to use, allowing dialysis dose determination in every dialysis treatment. Although a difference with the conventional method was observed, possible problems impacting the dialysis dose (e.g. shunt deterioration) may be detected early.

The automatic OCM with the urea distribution volume measured by BCM had a higher correlation with the conventional method. In stable patients a monthly determination of the urea distribution volume by BCM should be sufficient, enabling an automated control of dialysis dose in every dialysis treatment with low additional effort.

\section{References}

1 European Best Practice Guidelines for $\mathrm{He}$ modialysis: Part 1. Nephrol Dial Transplant 2002;17(suppl 7):S16-S31.

$\checkmark 2$ Coyne DW, Delmez J, Spence G, Windus DW: Impaired delivery of hemodialysis prescriptions: an analysis of causes and an approach to evaluation. J Am Soc Nephrol 1997;8:1315-1318.

-3 Press MH, Benz RL: Quantifying the role of factors that limit attainment of K/DOQI urea reduction ratio dialytic goal. Clin Nephrol 2006;66:98-102.

4 Kuhlmann U, Goldau R, Samadi N, Graf T, Gross M, Orlandini G, Lange H: Accuracy and safety of on-line clearance monitoring based on conductivity variation. Nephrol Dial Transplant 2001;16:1053-1058.

5 Racki S, Zaputović L, Maleta I, Grzetić M, Mavrić Z, Devcić B, Vujicić B: Assessment of hemodialysis adequacy by ionic dialysance: comparison to standard method of urea removal. Ren Fail 2005;27:601-604.
-6 Sternby J: Urea sensors - a world of possibilities. Adv Ren Replace Ther 1999;6:265272.

7 Castellarnau A, Werner M, Günthner R, Jakob M: Real-time Kt/V determination by ultraviolet absorbance in spent dialysate: technique validation. Kidney Int 2010 (E-pub ahead of print).

8 Daugirdas J: Second-generation logarithmic estimates of single-pool variable volume Kt/V: an analysis of error. J Am Soc Nephrol 1993;4:1205-1213

-9 Tattersall J, Martin-Malo A, Pedrini L, Basci A, Canaud B, Fouque D, Haage P, Konner K, Kooman J, Pizzarelli F, Tordoir J, Vennegoor M, Wanner C, ter Wee P, Vanholder EBPG guideline on dialysis strategies. Nephrol Dial Transplant 2007;22(suppl 2):ii5-ii21.

10 Ward RA, Ronco C: Improvements in technology: a path to safer and more effective hemodialysis. Blood Purif 2009;27:6-10.
11 Watson PE, Watson ID, Batt RD: Total body water volumes for adult males and females estimated from simple anthropometric measurements. Am J Clin Nutr 1980;33:27-39.

12 Wuepper A, Tattersall J, Kraemer M, Wilkie M, Edwards L: Determination of urea distribution volume for $\mathrm{Kt} / \mathrm{V}$ assessed by conductivity monitoring. Kidney Int 2003;64:22622271.

13 Moissl UM, Wabel P, Chamney PW, Bosaeus I, Levin NW, Bosy-Westphal A, Korth O, Müller MJ, Ellegård L, Malmros V, Kaitwatcharachai C, Kuhlmann MK, Zhu F, Fuller NJ: Body fluid volume determination via body composition spectroscopy in health and disease. Physiol Meas 2006;27:921-933.

14 Chamney PW, Wabel P, Moissl UM, Müller MJ, Bosy-Westphal A, Korth O, Fuller NJ: A whole-body model to distinguish excess fluid from the hydration of major body tissues. Am J Clin Nutr 2007;85:80-89. 
15 Wizemann V, Rode C, Wabel P: Whole-body spectroscopy (BCM) in the assessment of normovolemia in hemodialysis patients. Contrib Nephrol. Basel, Karger, 2008, vol 161, pp 115-118.

-16 Lindley EJ, Chamney PW, Wuepper A, Ingles $\mathrm{H}$, Tattersall JE, Will EJ: A comparison of methods for determining urea distribution volume for routine use in on-line monitoring of hemodialysis adequacy. Nephrol Dial Transplant 2009;24:211-216.

17 Wabel P, Chamney P, Moissl U, Jirka T: Importance of whole-body bioimpedance spectroscopy for the management of fluid balance. Blood Purif 2009;27:75-80.

-18 Passauer J, Petrov H, Schleser A, Leicht J: Pucalka K: Evaluation of clinical dry weight assessment in haemodialysis patients using bioimpedance spectroscopy: a cross-sectional study. Nephrol Dial Transplant 2010; 25:545-551.

19 Ronco C: Evolution of hemodiafiltration. Contrib Nephrol. Basel, Karger, 2007, vol 158, pp 9-19.

20 Bland JM, Altman DG: Statistical methods for assessing agreement between two methods of clinical measurement. Lancet 1986;1: 307-310.

-21 Lin L: A concordance correlation coefficient to evaluate reproducibility. Biometrics 1989; 45:255-268.

-22 Prado M, Roa LM, Palma A, Milán JA: Double target comparison of blood-side methods for measuring the hemodialysis dose. Kidney Int 2005;68:863-876.
23 Arogundade F, Barsoum RS: Indices for assessment of hemodialysis adequacy: a comparison of different formulae. Hemodial Int $2005 ; 9: 325-331$

-24 Beto JA, Bansal VK, Ing TS, Daugirdas JT: Variation in blood sample collection for determination of hemodialysis adequacy. Council on Renal Nutrition National Research Question Collaborative Study Group. Am J Kidney Dis 1998;31:135-141.

$>25$ Geddes CC, Traynor J, Walbaum D, Fox JG, Mactier RA: A new method of post-dialysis blood urea sampling: the 'stop dialysate flow' method. Nephrol Dial Transplant 2000;15: 517-523.

26 Lindsay RM, Sternby J: Future directions in dialysis quantification. Semin Dial 2001;14: 300-307.

27 Wallin O, Söderberg J, Van Guelpen B, Stenlund $\mathrm{H}$, Grankvist K, Brulin C: Preanalytical venous blood sampling practices demand improvement - a survey of test-request management, test-tube labelling and information search procedures. Clin Chim Acta 2008; 391:91-97.

28 Jensen EA, Stahl M, Brandslund I, Grinsted P: Stability of heparin blood samples during transport based on defined pre-analytical quality goals. Clin Chem Lab Med 2008;46: 225-234.

29 Daugirdas JT, Blake PG, Ing TS (eds): Handbook of Dialysis, ed 4. Philadelphia, Lippincott, 2007, p 154.

30 Katopodis KP, Hoenich NA: Accuracy and clinical utility of dialysis dose measurement using online ionic dialysance. Clin Nephrol 2002;57:215-220.
31 Santoro A: Confounding factors in the assessment of delivered hemodialysis dose. Kidney Int 2000;58:S19-S27.

-32 Kloppenburg WD, Stegeman CA, de Jong PE, Huisman RM: Anthropometry-based equations overestimate the urea distribution volume in hemodialysis patients. Kidney Int 2001;59:1165-1174.

33 Tzamaloukas AH, Murata GH, Vanderjagt DJ, Servilla KS, Glew RH: Body composition evaluation in peritoneal dialysis patients using anthropometric formulas estimating body water. Adv Perit Dial 2003;19:212-216.

-34 Daugirdas JT, Greene T, Depner TA, Chumlea C, Rocco MJ, Chertow GM: Anthropometrically estimated total body water volumes are larger than modeled urea volume in chronic hemodialysis patients: effects of age, race, and gender. Kidney Int 2003;64:11081119.

>35 Ikizler TA, Sezer MT, Flakoll PJ, Hariachar S, Kanagasundaram NS, Gritter N, Knights S, Shyr Y, Paganini E, Hakim RM, Himmelfarb J: Urea space and total body water measurements by stable isotopes in patients with acute renal failure. Kidney Int 2004;65:725732 .

36 Wizemann V, Wabel P, Chamney P, Zaluska W, Moissl U, Rode C, Malecka-Masalska T, Marcelli D: The mortality risk of overhydration in haemodialysis patients. Nephrol Dial Transplant 2009;24:1574-1579. 